\title{
Space and Habitat Use by Male and Female Raccoons, Procyon lotor, in Kansas
}

\author{
JAN F. KAMLER ${ }^{1}$ AND PHILIP S. GIPSON
}

Kansas Cooperative Fish and Wildlife Research Unit, U.S. Geological Survey, 205 Leasure Hall, Division of Biology, Kansas State University, Manhattan, Kansas 66506 USA

${ }^{1}$ Present address: Polish Academy of Sciences, Mammal Research Institute, 17-230 Bialowieza, Poland

Kamler, Jan F., and Philip S. Gipson. 2003. Space and habitat use by male and female Raccoons, Procyon lotor, in Kansas. Canadian Field-Naturalist 117(2): 218-223.

We monitored 12 radio-tagged adult Raccoons (Procyon lotor) from an unexploited population in northeastern Kansas to determine intersexual differences in space and habitat use. Home ranges (mean \pm SE) of males were relatively large (266 \pm 14 ha) and mutually exclusive, whereas home ranges of females were relatively small (122 \pm 52 ha) and overlapped extensively. Sizes of home ranges were smaller $(\mathrm{P}<0.05)$ in winter than summer for both sexes, although females reduced their home ranges more than males. Females used more grassland habitats than males during summer $(\mathrm{P}<0.05)$, whereas males used more grassland habitats than females during winter $(\mathrm{P}<0.05)$. Seasonal differences in habitat selection was detected for females $(\mathrm{P}<0.05)$, but not males. Intersexual differences in space and habitat use were likely related to different behavioral strategies employed by male and female Raccoons.

Key Words: Procyon lotor, Raccoon, habitat selection, home range, Kansas.

Raccoons (Procyon lotor), like most solitary carnivores, exhibit intersexual differences in home range sizes and spacing patterns (Kaufmann 1982; Sanderson 1987; Sandell 1989), with male home ranges larger than those of females (Fritzell 1978a; Sherfy and Chapman 1980; Lehman 1984; Seidensticker et al. 1988; Gehrt and Fritzell 1997). Although Raccoons exhibit sexual dimorphism, the large size of male home ranges cannot be explained by energetics alone (Gehrt and Fritzell 1997). Intersexual differences in home ranges and spacing patterns of Raccoons are likely related to different behavioral tactics employed by male and female Raccoons (Sandell 1989; Gehrt and Fritzell 1997, 1998). Little is known about intersexual differences in habitat use by Raccoons. Because different behavioral strategies employed by male and female Raccoons have been shown to affect home range sizes and spacing patterns, behavioral differences might also affect habitat use. Additionally, Raccoons are known to decrease activity during winter, especially in more northern latitudes, as ambient temperatures and food resources decrease (Schneider et al. 1971; Glueck et al. 1988). However, it is not known if male and female Raccoons respond differently to seasonal changes in temperature and food availability.

Although there have been numerous studies of Raccoons, few occurred in unexploited populations (Seidensticker et al. 1988; Gehrt and Fritzell 1997). To better understand evolutionary significant situations among carnivores, research is needed on unexploited populations in native habitats (Crabtree and Sheldon 1999). Finally, Raccoons are generally considered to be arboreal, yet little is known about Raccoon ecology within prairie-dominated ecosystems of the Great Plains.
The objectives of this study were to determine sexual and seasonal differences in home range sizes and habitat use of Raccoons from an unexploited population in a prairie-dominated ecosystem in northeastern Kansas. We tested the null hypotheses that (1) there were no seasonal differences in home range sizes between sexes, (2) there were no seasonal differences in home range sizes within sexes, (3) there were no seasonal differences in habitat use between sexes, and 4) there were no seasonal differences in habitat use within sexes.

\section{Study Area}

This study was conducted on Fort Riley Military Reservation (Fort Riley) in Geary, Riley and Clay counties, Kansas ( $\left.39^{\circ} 11^{\prime} \mathrm{N}, 96^{\circ} 77^{\prime} \mathrm{W}\right)$. Fort Riley is a 40,273-ha permanent U.S. Army Forces Command installation located in the Flint Hills Region of northeastern Kansas. The vegetative community is dominated by tall and mixed-grass prairie, interspersed with woodlands along the floodplain and within the lowlands of small drainages and ravines (U.S. Army 1994*). Major grasses include big bluestem (Andropogon gerardii), indian grass (Sorghastrum nutans), switchgrass (Panicum virgatum), little bluestem (Scizachyrium scoparium), and sideoats gramma (Bouteloua curtipendula) (U.S. Army 1994*). Woodlands within the small stream valleys and ravines are dominated by bur oak (Quercus macrocarpa), chinkapin oak (Quercus muhlenbergii), American elm (Ulmus americana), red mulberry (Morus rubra), bitternut hickory (Carya cordiformis), black walnut (Juglans nigra), green ash (Fraxinus pennsylvanica), hackberry (Celtis occidentalis), and honey locust (Gleditsia triacanthos-U.S. Army 1994*).

Fort Riley has a temperate continental climate characterized by hot summers, cold, dry winters, moderate 
winds, low humidity and a pronounced peak in rainfall late in the spring and in the first half of summer (U.S. Army 1994*). Mean daily high temperatures in January and July are $4.2^{\circ} \mathrm{C}$ and $33.7^{\circ} \mathrm{C}$, respectively. Mean daily low temperatures in January and July are $-7.8^{\circ} \mathrm{C}$ and $19.5^{\circ} \mathrm{C}$, respectively. Mean annual precipitation is $80.4 \mathrm{~cm}$ and ranges from $40.6 \mathrm{~cm}$ to 142.2 cm (U.S. Army 1994*).

Fort Riley has been opened to public hunting since 1982, although trapping is prohibited. Hunters must check in on a daily basis and report all animals harvested. Raccoons are not frequently harvested on Fort Riley, and no harvests were reported from 1995 to 1998.

\section{Methods and Materials}

We captured Raccoons during 4 periods: OctoberDecember 1995, January-April 1996, October-November 1996, and March-June 1997. We captured Raccoons in wire box traps baited with sardines and checked daily. We set traps in a 250-ha area in the southern region of Fort Riley to increase the likelihood that study animals would overlap in space and resource use. We immobilized Raccoons with an intramuscular injection of ketamine hydrochloride and acepromazine $(10: 1$ ratio, dosage $=0.2 \mathrm{ml} / \mathrm{kg})$. Our capture and handling protocol, no. 1098, was approved by the Institution Animal Use and Care Committee at Kansas State University. We recorded the following data for all captured Raccoons: body mass, body length, tail length, ear length, hindfoot length, shoulder height, sex, reproductive condition, age class, ear tag number, injuries, and ectoparasite load. Body mass was compared between sexes using t-tests (SAS Institute 1985). At time of capture, male Raccoons were aged according to body size and toothwear (Grau et al. 1970), and for females, size and pigmentation of teats (Kaufmann 1982). Raccoons were considered adult if they were $>1.5$ year old at time of capture, whereas all other raccoons were considered juveniles. Forty-four Raccoons were captured 61 times, including 5 adult males, 9 adult females, 13 juvenile males, and 17 juvenile females. Radio-transmitter collars (Advanced Telemetry Systems, Inc., Isanti, Minnesota 55040) were placed on all adults captured (5 males, 9 females) for this study. Due to early deaths, 2 Raccoons ( 1 male, 1 female) were not monitored long enough to be used in analyses.

We analyzed radio-telemetry data in two seasons defined as summer (April-September) and winter (October-March). The two seasons were defined in this way to parallel major changes in climate and animal responses to climatic change. Our delineations of two climatic seasons encompassed several phases of the raccoon reproductive cycle (Kaufmann 1982); however, climatic influences on raccoon movements likely obscure reproductive influences (Schneider et al. 1971), especially in higher latitudes where seasonal differences are more pronounced.
We recorded telemetry locations for each raccoon 1-2 times per week and $>12$ hours apart, which we considered sufficient to establish independence (White and Garrott 1990). We radio-tracked Raccoons simultaneously from two vehicles using null-peak systems which consisted of dual, four-element Yagi antennas. We conducted radio-tracking primarily during 18000900 hours, when Raccoons were likely to be most active (Kaufmann 1982; Sanderson 1987). We calculated location estimates using the maximum likelihood estimation option in the program Locate II (Pacer, Inc., Truro, Nova Scotia). Mean error for reference collars (known locations) was $65 \mathrm{~m}$ (95\% of errors were $\leq 166 \mathrm{~m}$ ).

We calculated seasonal and annual sizes of home ranges of Raccoons using the 95\% minimum convex polygon method (Mohr 1947), as calculated by CALHOME (Kie et al. 1994). We calculated annual home ranges for Raccoons with $>50$ locations (mean $\pm \mathrm{SD}=60 \pm 6)$ and $\geq 10$ months of radio-tracking. Area observation curves (Odum and Kuenzler 1955) showed that 21-24 locations were needed to effectively determine seasonal home ranges for individual Raccoons. Therefore, we calculated seasonal home ranges for Raccoons with $>25$ locations $(29 \pm 3)$ and $>3$ months of radio-tracking per season. Seasonal home ranges during summer were pooled across years. We compared seasonal and sexual differences in home range sizes using 2-tailed t-tests (SAS Institute 1985).

Habitat types were delineated using geographic information system (GIS) data provided by the Conservation Division at Fort Riley. Habitat types on Fort Riley were classified at $2 \mathrm{~m}$ resolution as grassland, woodland, built areas, water or sandy areas (Lauver et al. 1996*). Grassland was defined as all pasture (hayfield), rangeland, and other herbaceous cover having insufficient trees and/or shrubs to be classified as "woodland." Woodland was defined as wooded areas with $>15 \%$ canopy closure. Built areas were defined as areas of intensive use with much of the land covered by structures. Water included all water bodies larger than the minimum mapping unit of $2 \mathrm{~m}$. Sandy areas were defined as river sand bars, rock quarries, sand and gravel pits and other permanently exposed ground (Lauver et al. 1996*). The placement of land cover boundaries had a spatial accuracy of $\pm 10 \mathrm{~m}$ (Lauver et al. 1996*). Total coverage of these habitat types on Fort Riley was $82 \%$ grasslands, $16 \%$ woodlands, $2 \%$ built areas, and a trace of both water and sandy areas. Total coverage of the 250-ha trapping area consisted of $62 \%$ grasslands, $37 \%$ woodlands, and $1 \%$ built areas.

We determined habitat use and availability for each raccoon using the computer program ArcView GIS (Version 3.0, Environmental Systems Research Institute, Inc., Redlands, California 92373). We calculated selection indices by dividing observed numbers of locations by expected numbers of locations for each habitat type. We calculated the expected number of 
locations for each habitat type as the total number of locations inside the home range multiplied by the proportion of home range consisting of that habitat (Kamler 1998). A habitat selection index $>1$ indicates greater than expected use for that habitat type; an index $<1$ indicates less than expected use for that habitat type. We used log-transformed selection indices (Zar 1984) and 2-tailed t-tests to compare habitat selections between seasons and between sexes. We used only selection indices for grassland habitat to determine statistical differences because it was the most dominant habitat type in the study area, and analyses of other habitat types would not have been independent (Kamler 1998).

\section{Results}

Three Raccoons (females) were monitored from April to September 1996, and 9 Raccoons (5 females, 4 males) were monitored from April 1997 to March 1998. Annual and seasonal home ranges of male Raccoons were larger than those of females $(\mathrm{P}<0.05)$. Home range size (mean \pm SE) in summer was $244 \pm$ $26 \mathrm{ha}(\mathrm{n}=4)$ for males, and $103 \pm 10 \mathrm{ha}(\mathrm{n}=8)$ for females. The home range size in winter was $193 \pm 11$ ha $(n=4)$ for males, and $52 \pm 12$ ha $(n=4)$ for females. Annual home range of male Raccoons, 266 \pm 14 ha $(n=4)$, was more than twice as large as that of females, $122 \pm 52$ ha $(\mathrm{n}=4)$. Home ranges of female Raccoons decreased $(\mathrm{P}<0.05)$ by $50 \%$ from summer to winter, whereas home ranges of males decreased $(\mathrm{P}<0.05)$ by $21 \%$ from summer to winter. Home ranges of females raccoons overlapped extensively, whereas home ranges of males were exclusive (Figure 1). A fifth adult male that died before relevant data were collected had a capture and death location outside the home range boundary of the other adult males (Figure 1). The mass (mean $\pm \mathrm{SE}$ ) of males $(9.1 \pm 0.6 \mathrm{~kg})$ was larger $(\mathrm{P}<0.05)$ than that of females $(7.0 \pm 0.4 \mathrm{~kg})$.

Both male and female Raccoons generally selected grasslands less than expected, and woodlands more than expected (Table 1). Habitat selection of females differed $(\mathrm{P}<0.05)$ between seasons, as selection of grassland habitats decreased from summer $(0.90)$ to winter (0.49) (Table 1). Habitat selections of males did not differ $(\mathrm{P}=0.22)$ between summer $(0.64)$ and winter (0.84) (Table 1). Female Raccoons selected more $(\mathrm{P}<0.05)$ grassland habitats than males during summer, whereas males selected more $(\mathrm{P}<0.05)$ grassland habitats than females during winter (Table 1). Habitat selection indices of Raccoons were relatively consistent within sexes despite availability of grassland habitat in individual home ranges varying from $31-83 \%$ in summer and $16-77 \%$ in winter.

\section{Discussion}

Although male Raccoons are larger than females, the large size of male home ranges cannot be explained by energetic requirements alone (Gehrt and Fritzell 1997). The larger home ranges of male Raccoons are likely a result of different behavioral tactics employed by male and female Raccoons (Sandell 1989; Gehrt and Fritzell 1997, 1998). Females rear young by themselves, so their movements and home range sizes are closely related to energetic demands and available resources (Sandell 1989; Gehrt and Fritzell 1997, 1998). In contrast, males are polygynous and free of raising young, so their movements and home range sizes are more closely related to access and distribution of females (Sandell 1989; Gehrt and Fritzell 1997, 1998).

Seasonal fluctuations in mean home range sizes of Raccoons were not observed in the southern United States (Gehrt and Fritzell 1997), but were observed in more northern areas (Schneider et al. 1971; Glueck et al. 1988). The reductions in home range sizes from summer to winter in this study were likely the result of reduced activity of Raccoons in winter (Schneider et al. 1971; Glueck et al. 1988). Raccoons are known to lose weight during winter after a fat build-up during summer and early fall (Mech et al. 1968; Johnson 1970; Moore and Kennedy 1985; Zeveloff and Doerr 1985). They may reduce activity and forage less in winter because they can rely more on fat for their ener-

TABLE 1. Habitat selection indices ${ }^{\text {a }}$ of adult Raccoons monitored on Fort Riley Military Reservation, Kansas, April 1996 to March 1998.

\begin{tabular}{|c|c|c|c|c|c|c|}
\hline \multirow[b]{2}{*}{ Season } & \multirow[b]{2}{*}{ Sex } & \multirow[b]{2}{*}{$\mathrm{n}$} & \multicolumn{2}{|c|}{ Grassland } & \multicolumn{2}{|c|}{ Woodland } \\
\hline & & & Mean \pm SE & Range & Mean \pm SE & Range \\
\hline \multirow[t]{2}{*}{ Summer } & female & 8 & $0.90 \pm 0.08$ & $0.60-1.30$ & $1.16 \pm 0.12$ & $0.72-1.68$ \\
\hline & male & 4 & $0.64 \pm 0.06$ & $0.55-0.82$ & $1.58 \pm 0.23$ & $1.20-2.19$ \\
\hline \multirow[t]{2}{*}{ Winter } & female & $4^{b}$ & $0.49 \pm 0.07$ & $0.37-0.69$ & $1.63 \pm 0.27$ & $1.12-2.13$ \\
\hline & male & 4 & $0.84 \pm 0.15$ & $0.65-1.29$ & $1.42 \pm 0.32$ & $0.91-2.36$ \\
\hline
\end{tabular}

${ }^{a}$ Habitat selection indices were calculated by dividing the percentage of that habitat type used by the percentage of that habitat type available. Habitat selection indices $>1$ indicate greater than expected use, and indices $<1$ indicate less than expected use.

${ }^{\mathrm{b}}$ Four females were not monitored long enough ( $>3$ months) during winter for habitat analyses. 


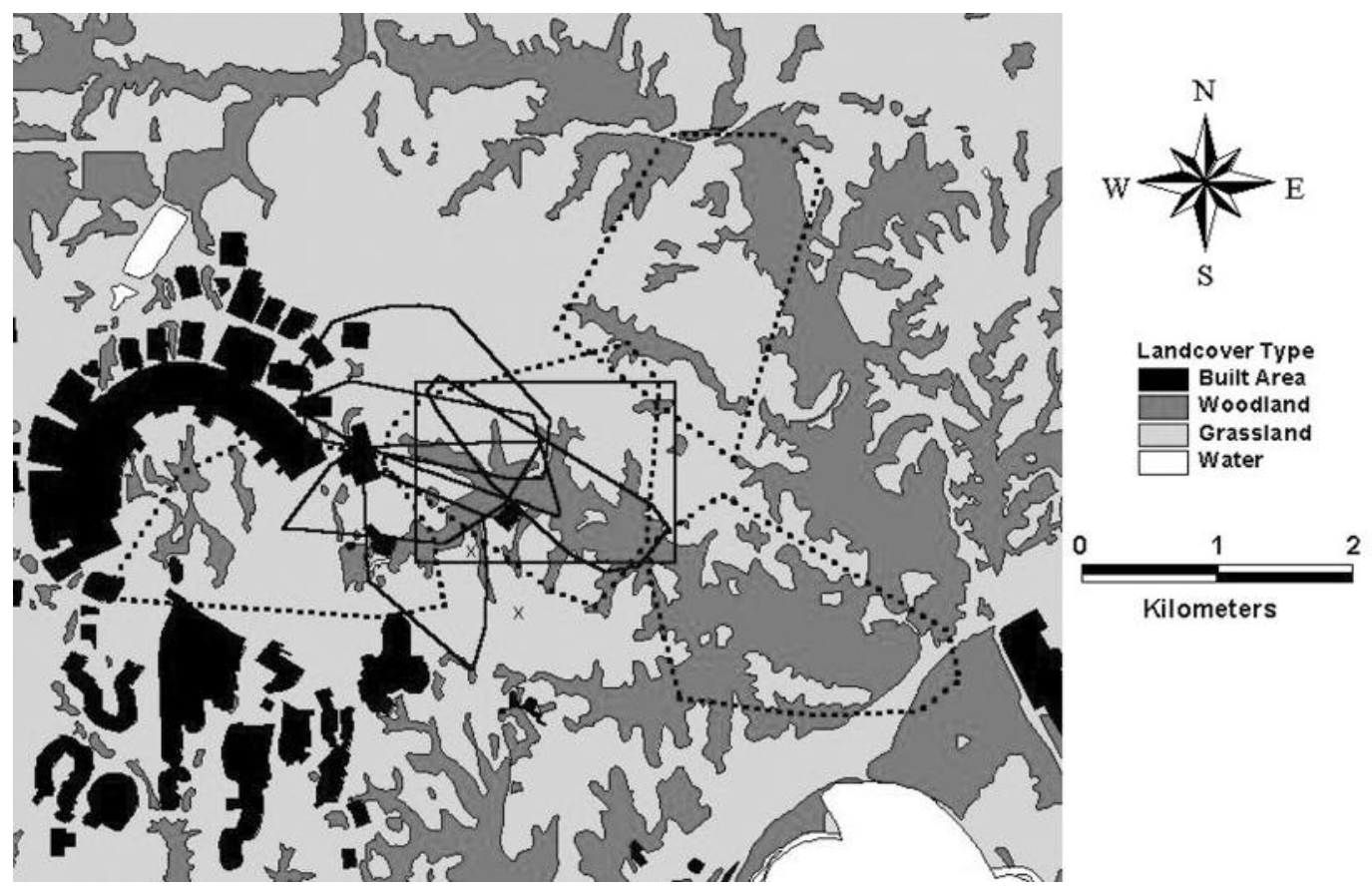

FIGURE 1. Summer home ranges of adult Raccoons monitored in 1997 on Fort Riley Military Reservation, Kansas (similar patterns were observed in other seasons and years). Solid polygons represent females $(n=5)$, whereas dashed polygons represent males $(n=4)$. The "X" represents the capture and death locations, of another adult male that died before relevant data were collected. Solid rectangle represents 250-ha trapping area.

getic demands. Foraging in winter may also be more energetically demanding than in summer because of the decrease in ambient temperature and reductions in food resources. A majority of Raccoon diets, including fruits, nuts, invertebrates, and small aquatic and terrestrial vertebrates (Kaufmann 1982; Smith et al. 1987), are reduced in abundance or absent during winter in temperate regions.

In winter, male Raccoons had a smaller reduction in home range than did females. This may have been due to home range maintenance by male Raccoons. When males are polygynous and have exclusive home ranges, competition over access to areas with many females probably goes on for most of the year (Sandell 1989). Therefore, males that have acquired home ranges should show their presence there throughout the year because it is easier to maintain an exclusive home range than to establish one (Sandell 1989). Additionally, reproductive activities can influence home range sizes of solitary carnivores (Sandell 1989), including Raccoons (Fritzell 1978b). Because winter includes the breeding period for Raccoons in Kansas (Bee et al. 1981), male Raccoons could have maintained larger home ranges than females due to inreased movements related to breeding activities (Seidensticker et al. 1988).
On our study site, home ranges of adult females overlapped extensively, whereas home ranges of adult males were exclusive (Figure 1). Non-overlapping home ranges of male Raccoons may have been a result of a small sample; however, previous studies showed that although home ranges of females overlapped throughout their range, home ranges of males may or may not overlap (Fritzell 1978a; Lehman 1984; Seidensticker et al. 1988; Gehrt and Fritzell 1997). Reasons for variability in home range overlap of male Raccoons may be related to both the degree of human exploitation, and social status of males that were monitored. For example, degree of human exploitation can contribute to variability in social organizations of carnivores (Crabtree and Sheldon 1999), so unexploited populations likely exhibit more stable social organizations than exploited ones. Additionally, previous research from unexploited populations of Raccoons showed that although home ranges of subordinate males overlapped, the home ranges of the most dominant males did not overlap (Gehrt and Fritzell 1997, 1999). Because dominance of male Raccoons is positively related to size (Gehrt and Fritzell 1999), the home ranges of the largest males may not overlap. The five males (including the male that had an early death) monitored in our study were the largest (8-11 
$\mathrm{kg}$ ) captured in 2.5 years of trapping, suggesting that they were the most dominant males in our study site. Thirteen juvenile males were also captured during the study, suggesting that home ranges of more numerous younger males likely overlapped those of large adult males.

Habitat selections differed between males and females in both seasons, possibly as a result of energetic differences between the sexes. In summer, females may have selected more grasslands than males due to differences in energetic requirements as a result of rearing young. Previous studies also found intersexual differences in habitat use of Raccoons, especially during the rearing season (Fritzell 1978b; Sherfy and Chapman 1980; Endres and Smith 1993). Sexual differences in habitat use by Raccoons may have also resulted from sexual dimorphism, which can lead to sexual segregation in habitat use and niche partitioning (Selander 1966; Moors 1980).

In winter, females selected less grassland and more woodland than males. Woodlands contain tree cavities that provide cover and protection from predators, especially as females decrease movements and become less active as a result of pregnancy (Endres and Smith 1993). During our study, three female Raccoons died from predation during winter and early spring, suggesting that females were more vulnerable to predation during this period (Kamler 1998). Seasonal differences in habitat use by males did not differ, probably as a result of their continuous home range maintenance. Females likely exhibit greater fluctuations in energetic requirements, and consequently greater variability in habitat use, as they rear young during summer, but become less active and pregnant during winter. Thus, the evolutionary and behavioral factors that contribute to intersexual differences in raccoon home range sizes also likely contributed to intersexual differences in their habitat selections.

\section{Acknowledgments}

We thank D. Jones, H. Abel, M. Pont, Carin Richardson and other personnel at the Conservation Division on Fort Riley for their assistance. We also thank J. Beckman, B. Bowman, J. Boyer, M. Dryden, J. Goheen, D. Hogan, B. Kamler, D. Martin, C. Perchellet, T. Snyder, Chad Richardson, and G. Truan for assistance with field work and other aspects of the project. We thank K. Kauhala and other reviewers for helpful comments on this paper. This project was funded by the Department of Defense, in cooperation with the Kansas Cooperative Fish and Wildlife Research Unit, U.S. Geological Survey, and Kansas State University.

\section{Documents Cited (marked * in text)}

Lauver, C. L., W. H. Busby, K. Kindscher, and J. L. Whistler. 1996. Identification and delineation of loggerhead shrike habitat on the Fort Riley Military Reservation. Kansas Biological Survey Report 69. 29 pages.
U. S. Army. 1994. Integrated natural resource management plan for Fort Riley, Kansas. Louis Berger and Associates, Inc., Washington, D.C. 161 pages.

\section{Literature Cited}

Bee, J. W., G. E. Glass, R. S. Hoffmann, and R. R. Patterson. 1981. Mammals in Kansas. University of Kansas Printing Service, Lawrence, Kansas. 300 pages.

Crabtree, R. L., and J. W. Sheldon. 1999. Coyotes and canid coexistence in Yellowstone. Pages 127-163 in Carnivores in ecosystems: the Yellowstone experience. Edited by T. W. Clark, A. P. Curlee, S. C. Minta, and P. M. Kareiva. Yale University Press, New Haven, Connecticut.

Endres, K. M., and W. P. Smith. 1993. Influence of age, sex, season and availability on den selection by raccoons within the central basin of Tennessee. American Midland Naturalist 129: 116-131.

Fritzell, E. K. 1978a. Aspects of raccoon (Procyon lotor) social organization. Canadian Journal of Zoology 56: 260-271.

Fritzell, E. K. 1978b. Habitat use by prairie raccoons during the waterfowl breeding season. Journal of Wildlife Management 42: 118-127.

Gehrt, S. D., and E. K. Fritzell. 1997. Sexual differences in home ranges of raccoons. Journal of Mammalogy 78: 921-931.

Gehrt, S. D., and E. K. Fritzell. 1998. Resource distribution, female home range dispersion and male spatial interactions: group structure in a solitary carnivore. Animal Behaviour 55: 1211-1227.

Gehrt, S. D., and E. K. Fritzell. 1999. Behavioral aspects of the raccoon mating system: determinants of consortship success. Animal Behaviour 57: 593-601.

Glueck, T. F., W. R. Clark, and R. D. Andrews. 1988. Raccoon movement and habitat use during the fur harvest season. Wildlife Society Bulletin 16: 6-11.

Grau, G. A., G. C. Sanderson, and J. P. Rogers. 1970. Age determination of raccoons. Journal of Wildlife Management 34: 364-372.

Johnson, A. S. 1970. Biology of the raccoon in Alabama. Alabama Agricultural Experiment Station Bulletin 402: 1-148.

Kamler, J. F. 1998. Ecology and interspecific relationships of mammalian predators on Fort Riley Military Reservation, Kansas. M.S. thesis. Kansas State University, Manhattan. 150 pages.

Kaufmann, J. H. 1982. Raccoon and allies. Pages 567-585 in Wild mammals of North America. Edited by J. A. Chapman and G. A. Feldhamer. The John Hopkins University Press, Baltimore, Maryland.

Kie, J. G., J. A. Baldwin, and C. J. Evans. 1994. CALHOME: home range analysis program. U.S. Forest Service, Pacific Southwest Research Station, Fresno, California. 19 pages.

Lehman, L. E. 1984. Raccoon density, home range, and habitat use on south-central Indiana farmland. Indiana Department of Natural Resources P-R Bulletin 15: 1-66.

Mech, L. D., D. M. Barnes, and J. R. Tester. 1968. Seasonal weight changes, mortality, and population structure of raccoons in Minnesota. Journal of Mammalogy 49: 63-73.

Mohr, C. O. 1947. Table of equivalent populations of North American small mammals. American Midland Naturalist 37: 223-249.

Moore, D. W., and M. L. Kennedy. 1985. Weight changes and population structure of raccoons in western Tennessee. Journal of Wildlife Management 49: 906-909. 
Moors, P. J. 1980. Sexual dimorphism in the body size of mustelids (Carnivora): the roles of food habits and breeding systems. Oikos 34: 147-158.

Odum, E. P., and E. J. Kuenzler. 1955. Measurement of territory and home range size in birds. Auk 72: 128-137.

Sandell, M. 1989. The mating tactics and spacing patterns of solitary carnivores. Pages 164-182 in Carnivore behavior, ecology, and evolution. Edited by J. L. Gittleman. Cornell University Press, Ithaca, New York.

Sanderson, G. C. 1987. Raccoon. Pages 486-499 in Wild Furbearer Management and Conservation in North America. Edited by M. J. Novak, J. A. Baker, M. E. Obbard, and B. Malloch. Ministry of Natural Resources, Ontario.

SAS Institute. 1985. SAS user's guide: statistics, 5th edition. SAS Institute, Inc., Cary, North Carolina. 956 pages.

Schneider, D. G., L. D. Mech, and J. R. Tester. 1971. Movements of female raccoons and their young as determined by radio-tracking. Animal Behaviour Monographs 4: 1-43.

Seidensticker, J., A. J. T. Johnsingh, R. Ross, G. Sanders, and M. B. Webb. 1988. Raccoons and rabies in Appalachian Mountain Hollows. National Geographic Research
4: 359-370.

Selander, R. K. 1966. Sexual size dimorphism and differential niche utilization in birds. Condor 68: 113-151.

Sherfy, F. C., and J. A. Chapman. 1980. Seasonal home range and habitat utilization of raccoons in Maryland. Carnivore 3: 8-18.

Smith, R. A., M. L. Kennedy, and G. D. Baumgardner. 1987. Food habits of the raccoon (Procyon lotor) at Land Between the Lakes. Journal of the Tennessee Academy of Science 62: 79-82.

White, G. C., and R. A. Garrott. 1990. Analysis of radiotracking data. Academic Press, Inc., San Diego, California. 383 pages.

Zar, J. H. 1984. Biostatistical analysis, 2nd edition. Prentice-Hall, Inc., Englewood Cliffs, New Jersey. 718 pages.

Zeveloff, S. I., and P. D. Doerr. 1985. Seasonal weight changes in Raccoons (Carnivora: Procyonidae) of North Carolina. Brimleyana 11: 63-67.

Received 4 April 2001

Accepted 25 November 2003 